\title{
Un estudio etiológico de los errores morfosintácticos y gramaticales en la interlengua de aprendices brasileños de español: un análisis de la categoría «verbos»
}

\author{
ANA LUISA CARDOSO \\ Centro de Estudios del Español como \\ Lengua Extranjera (CELE) \\ Universidad Nacional de Rosario (UNR) \\ Argentina \\ analu.car@hotmail.com
}

\author{
MARÍA ISABEL POZZO \\ Centro de Estudios del Español como \\ Lengua Extranjera (CELE) \\ Universidad Nacional de Rosario (UNR) \\ Consejo Nacional de Investigaciones \\ Científicas y Técnicas (CONICET) \\ Argentina \\ maria.isabel.pozzo@gmail.com
}

\section{Resumen}

En este artículo nos proponemos presentar los errores etiológicos - inter e intralingüísticos verificados en la interlengua de brasileños hablantes/aprendientes de Español. Más específicamente damos énfasis a las dificultades que estos hablantes tienen en el empleo de los verbos en español. En este estudio, identificamos los errores, los clasificamos, los describimos y explicamos sus posibles causas. Analizamos, para ello, las pruebas de producción escrita del examen de dominio de la lengua aplicado por universidades argentinas - el Certificado de Español: Lengua y Uso (CELU). Nos proponemos compartir los resultados obtenidos por medio de esta investigación y promover en el docente de lengua española para brasileños una reflexión acerca de las dificultades que este grupo meta tiene en el uso de los verbos en español, especialmente teniendo en cuenta la proximidad de las lenguas portuguesa y española, hecho que no siempre es un factor positivo en este proceso de aprendizaje. Esperamos, además, que dicha reflexión pueda llevar el docente a buscar estrategias didácticas que saquen provecho de los errores de estos alumnos para su aprendizaje del español.

\section{Palabras clave}

Interlengua, aprendices brasileños de español, errores etiológicos, errores interlingüísticos, errores intralingüísticos, errores verbales. 


\title{
An etiological study of morphosyntactic and grammatical errors in the interlanguage of Brazilian learners of Spanish: an analysis of the category "verbs"
}

\begin{abstract}
In this article we aim to present the etiological errors - inter and intralinguistic - found in the interlanguage of Brazilian speakers learning Spanish. More specifically, we emphasize the difficulties that these learners have in the use of verbs in Spanish. In this study, we identify, classify, describe and explain the errors and their possible causes. In order to achieve this goal, we analyze their written productions of the language proficiency test applied by Argentine universities - the Spanish Certificate: Language and Use (CELU). Our purpose is to share the results found through this research and to make the Spanish Language teacher of for Brazilians reflect on the difficulties that this target students has in the use of verbs in Spanish, especially taking into account the proximity of Portuguese and Spanish languages, which is not always a positive factor in this learning process. We also hope that this reflection can lead the teacher to seek didactic strategies that take advantage of their students'errors for the learning of the Spanish language.
\end{abstract}

\section{Keywords}

Interlanguage, Brazilian learners of Spanish, etiological errors, interlinguistic and intralinguistic errors, verbal errors.

Recibido el 26/08/2018

Aceptado el 18/03/2019 


\section{Introducción}

El presente artículo es resultado de un estudio comparativo realizado por medio de análisis de exámenes escritos de domino de la lengua española, de aprendices brasileños de español. El presente estudio puso atención a la interferencia que la lengua portuguesa refleja en las producciones lingüísticas en español de estos hablantes/aprendientes brasileños.

En razón de los cambios por los cuales ha pasado Brasil en su organización social, política y económica a lo largo de su historia y, más aún, en los últimos tiempos, el escenario de la enseñanza de lengua extranjera ha ganado significativa atención. En este contexto, además del inglés, el español también ha logrado importante papel.

Sin relegar el valor de la formación del alumno como ciudadano y, además, considerando el deseo brasileño de establecer una nueva relación con los países hispanohablantes, sobre todo con los que han firmado el Tratado del Mercado Común del Sur (MERCOSUR), se considera que, para jóvenes y futuros profesionales, el conocimiento de un segundo idioma se hace de gran importancia en la sociedad actual, dado que amplía el conocimiento de mundo (cultural, político, económico, social, lingüístico) de quien lo aprende $\mathrm{y}$, consecuentemente, abre nuevas oportunidades sociales y de trabajo.

Teniendo en cuenta la importancia del español dentro del contexto aquí presentado, muchos brasileños recurren a la realización de pruebas que certifiquen sus conocimientos acerca de la lengua española, puesto que tal certificación, además de darles autoconfianza en su desempeño real de la lengua, también agrega significativo valor a su currículo profesional.

Considerando estas razones, resulta de interés analizar el desempeño de aprendices brasileños que buscan una certificación de competencia en lengua española. Puesto que Brasil es parte del contexto sudamericano, consideramos, más precisamente, los exámenes aplicados para la obtención del Certificado de Español: Lengua y Uso (CELU), emitido por Argentina.

Según el Centro de Lenguas de la Universidad de São Paulo (USP), los brasileños son los principales postulantes al examen, razón por la cual es realizado en varias sedes de Argentina y de Brasil. Ello justifica el interés de nuestro estudio acerca de la competencia lingüística de brasileños que realizan este examen. 
Los niveles de dominio de la lengua tenidos en cuenta para este estudio son el intermedio y el avanzado. Dicha elección se debe al hecho de que en estos niveles los alumnos presentan mayor conocimiento de la lengua meta y los fenómenos observados se presentan más complejos para la investigación. Asimismo, son los dos niveles a los cuales el CELU otorga certificación.

Nuestra experiencia como docente nos ha enseñado la dificultad que presentan en la construcción morfosintáctica y gramatical en Español Lengua Extranjera (ELE), los aprendices brasileños de español, pues aunque sean lenguas próximas, presentan, cada una, sus peculiaridades morfológica-sintácticas-gramaticales. Ello nos ha estimulado a la investigación con la intención de enriquecer los estudios en esta área.

Aunque el resultado del análisis investigativo nos permitió identificar distintas categorías de errores, en este artículo nos centraremos en los errores de la categoría «verbos», considerando que fue la categoría que presentó el mayor número de errores cometidos por brasileños hablantes de español. Asimismo, el análisis de todas las categorías de errores contempladas en el estudio excedería los límites de este artículo.

\section{Estudios acerca de la interlengua de aprendices brasileños de} español

A continuación hacemos un breve recorrido por los estudios que se han realizado en los últimos años, acerca de esta especificidad de error, y que han contribuido en el estudio de la interlengua de aprendices brasileños de español.

Pavón (2009) contribuye en este campo de investigación con su tesis Análisis de errores, contrastivo e interlengua, en estudiantes brasileños de español como segunda lengua: verbos que rigen preposición y/o ausencia de ella. En él, la investigadora contempla un estudio contrastivo entre el portugués y el español, seguido de un análisis de errores en la interlengua de alumnos universitarios brasileños, centrándose, como nos indica el título de su trabajo, en los verbos que rigen preposición y/o ausencia de ella. Los resultados de esta investigación revelan que los tipos de errores, tanto en ámbito escrito como oral, son de varios tipos: interlingüísticos de transferencias, intralingüísticos, de tipo descriptivo, por falta de conocimiento de las reglas gramaticales, y, sobre todo en el nivel superior, errores fosilizados. Se concluye en este estudio que la lengua materna puede facilitar el aprendizaje de una L2 semejante en los 
niveles elementales, pero puede ser un factor negativo a la hora de dominar la lengua meta, ya que en niveles superiores se destacan los errores fosilizados.

Polakof (2009) elabora un análisis de errores en la expresión escrita de brasileños, en su investigación Análisis de errores léxico-sintáctico verbales en producciones escritas por aprendices brasileños de ELE. La investigadora se ocupa de analizar los errores léxico-sintáctico de esfera verbal cometidos por estudiantes brasileños que han sido evaluados en un curso de verano en una universidad de Uruguay. Los errores léxicosintáctico verbales analizados se refieren a las inadecuaciones que cometen los aprendices cuando fallan al combinar un sustantivo determinado con un verbo que cumple con la selección categorial y semántica dependiente de la lengua, pero no cumple con la dependiente de la norma ( ${ }^{*}$ hacer una merienda - tomar la merienda). En la investigación, la autora identificó los errores y los describió. Según la propia investigadora, su investigación es una contribución a los estudios del área y agrega que son necesarios otros análisis del tipo cuantitativo y de distintas categorías gramaticales para que se llegue a resultados más generalizados.

Silva Júnior (2010) ha realizado una investigación en el área del Análisis de Errores (AE) para la construcción de su tesis doctoral con el título Análisis de Errores. Estudio de las estructuras verbales y discursivas en el aprendizaje del español - LE por parte de alumnos brasileños (producción escrita). En su estudio el autor se centra en los errores discursivos y en el entorno verbal en la expresión escrita de alumnos brasileños de español en una universidad del norte de Brasil. El resultado revela 1.117 errores que corresponden al análisis morfosintáctico de las estructuras verbales y al uso de los marcadores discursivos. Los fallos en el uso de marcadores discursivos representan un número bastante pequeño y, según Silva Júnior, esto está relacionado al hecho de que los alumnos no tienen conocimiento de los marcadores discursivos en español y, por tanto, no los usan; esto es, producen oraciones más simples y cortas. Ello se debe a que en las clases de ELE, no solo los profesores, sino también los materiales didácticos, se centran en la gramática por sobre la competencia escrita. Respecto a los errores en general, el investigador apunta que los fallos, en gran parte, son de transferencia de la lengua materna y de adaptaciones gráficas por parte de los aprendientes.

Otro estudio interesante en esta área que puede ser considerado un análisis inverso es el de Ortiz (2011) con el Análisis de interlengua en un corpus de portugués escrito de estudiantes castellano hablantes universitarios. En él la investigadora presenta el análisis de errores y fenómenos de interlengua producidos por estudiantes de 
portugués lengua extranjera de un centro de lenguas de una universidad de México. En la investigación la autora determina cómo se configura esta interlengua, estableciendo las posibles causas de los errores. Fueron estudiados los problemas ortográficos, léxicos, gramaticales y los que pertenecen al campo de la interferencia lingüística. En la conclusión se expresa que: los errores son transitorios en la mayoría de los casos, frente a un menor número de errores fosilizados; gran parte de los errores se refieren a la producción de léxico, a la capacidad discursiva de los alumnos y a las confusiones y mezclas provocadas por la proximidad entre lenguas. Se advierte influencia de las estructuras del castellano en el proceso de aprendizaje, es decir, bastantes errores son provocados por la traducción literal de formas del castellano al portugués.

Gómez Seibane (2012) nos presenta algunas dificultades morfosintácticas de lusohablantes desde una perspectiva histórica de las lenguas, en su trabajo Dificultades morfosintácticas de lusohablantes en el aprendizaje de español: explicaciones desde la historia de la lengua. Sin embargo, se centra específicamente en cuatro categorías gramaticales: la adscripción de género de ciertos sustantivos y el empleo de «el» como artículo femenino; la colocación de pronombres átonos; los tratamientos personales; y la marcación preposicional del objeto directo, lo que difiere de nuestro trabajo, el cual contempló más categorías gramaticales (aunque en este artículo presentamos solo lo que se refiere a la categoría «Verbos») y se centra en explicar las interferencias del portugués en nuestro contexto contemporáneo.

La tesis doctoral de Rocha (2013) denominada Los errores léxicos en textos escritos en español por alumnos universitarios brasileños en formación como profesores de español lengua extranjera, se asemeja a nuestro trabajo. Sin embargo, la investigadora se direcciona al análisis de los errores de profesores brasileños de español que están en formación, mientras que nuestra investigación considera el público general que acude a un examen de dominio de la lengua y su certificación. Pensamos que la elección de un público general nos permite un análisis de un aprendizaje menos monitoreado, pero de igual relevancia al referirnos al dominio de la lengua.

También Torrijos (2015) presenta, en su tesis doctoral, Errores del uso del español en estudiantes extranjeros: creación de una taxonomía y su etiquetado, un trabajo bastante detallado. Sin embargo, considera estudiantes extranjeros de distintas nacionalidades, lo que no posibilita el estudio centrado a las interferencias del portugués. 
Para finalizar este punto, consideramos importante mencionar que no hemos encontrado investigaciones relacionadas al análisis de errores morfosintácticos y gramaticales en la interlengua escrita de aprendices brasileños de español que acuden al CELU como certificación de su competencia en lengua española. De esta forma, nuestro estudio puede, sin duda, enriquecer el conjunto de investigaciones realizadas hasta el momento y esperemos que venga a servir de ayuda tanto a profesores de ELE para brasileños como a alumnos brasileños aprendientes de español.

\section{Preguntas de la investigación}

A partir de lo expuesto, el objetivo principal de nuestro estudio fue analizar los errores recurrentes en producciones escritas de aprendices brasileños de español, de niveles intermedio y avanzado, que acuden a un examen de certificación en ELE. Hemos analizado, en específico, los tipos de errores dentro de un microsistema que contempla errores morfosintácticos y gramaticales, de modo de identificarlos, clasificarlos, describirlos y explicar sus posibles causas.

Tras la definición del objeto de estudio, nos planteamos algunas preguntas que motivaron nuestra investigación. Y aquí, en este artículo, las adaptamos de modo de contemplar exclusivamente la categoría «verbos».

1- ¿Cómo se expresa la frecuencia de las causas, inter e intralinguales, en los errores de la categoría «verbos» en la producción escrita de aprendices brasileños de español en nivel intermedio y avanzado? En otras palabras, considerando la proximidad de las lenguas española y portuguesa ¿las ocurrencias por interferencia de la lengua materna serán siempre superiores a las ocurrencias provenientes de factores de la propia lengua meta en esta categoría gramatical?

2- Al considerar los errores encontrados en la categoría «verbos», ¿cuáles de los errores etiológicos predominan: los interlingüísticos o los intralingüísticos?

3- ¿Existe la posibilidad de que algunos errores con «verbos» en la lengua meta puedan haber resultado de la interferencia y transferencia de errores en la propia lengua materna?

Estas son las preguntas que trataremos de contestar en el resto de este artículo. 


\section{Teorías y conceptos básicos de nuestro estudio}

\subsection{La interlengua}

Según Peris (2004: 477) la interlengua se caracteriza por «unas gramáticas que tienen sus propias reglas (provisionales y en evolución), reglas que no coinciden plenamente con las de la lengua meta». De acuerdo con estas teorías, el aprendiente atraviesa distintos estadios entre el nivel cero de competencia en la lengua meta y el que desea alcanzar.

Respecto a este sistema, Krashen (1977, citado por Tarone, 1983: 285) ha considerado el conocimiento metalingüístico y lo ha llamado de «Monitor» (teoría del Monitor). Según esta teoría, el monitor permite la introspección consciente y el alumno puede describirlo mediante reglas gramaticales formuladas conscientemente.

Para Tarone (1983), las producciones en segundas lenguas son variables sistemáticamente. De acuerdo con este investigador, «el contexto lingüístico puede tener un efecto variable en el uso que hace el alumno de estructuras lingüísticas» (Tarone, 1983: 265). Además, pone de relieve que la técnica utilizada para la obtención de los datos de los alumnos puede también tener un efecto variable sobre la producción, por parte de éstos, de estructuras de la interlengua.

Tarone (1983) parte del supuesto de que la capacidad en la interlengua del alumno no es homogénea (de un solo estilo), sino heterogénea, compuesta por un continuum de estilos -El Paradigma de la Capacidad Continua. Este sistema nos permite dar cuenta de la variabilidad de la interlengua, puesto que considera distintos estilos dentro de diferentes contextos. Desde esta perspectiva, el continuum es propio tanto de las lenguas naturales como de la interlengua y «cualquier sistema -incluyendo el de la interlengua- tiene su propio estilo cuidado, que puede definirse como el estilo que el hablante utiliza cuando presta la máxima atención a la forma de la lengua» (Tarone, 1983: 278-279).

Además, el presupuesto de Tarone incluye, en la capacidad del aprendiente, un estilo «vernáculo», el cual se evidencia cuando el alumno presta el menor grado de atención a la forma de la lengua. Así, el aprendizaje de las reglas y la capacidad del alumno va desde el estilo cuidado al estilo vernáculo y, entre estos estilos está el continuum intermedio de estilos que constituyen el sistema de la interlengua. En otras palabras, las estructuras de la lengua objeto se mueven desde el estilo cuidado hasta el 
vernáculo, y aquellas estructuras que aparecen espontáneamente en el estilo vernáculo serán reemplazadas gradualmente por las estructuras de la lengua objeto.

\subsection{La competencia lingüística o gramatical}

Inicialmente, ténganse en cuenta que la gramática a la cual nos referimos en este estudio se trata de la forma de la lengua, o sea, la construcción de enunciados que deben seguir unos principios que rigen la lengua. De ahí, tomamos como definición de gramática la que nos presenta el Marco Común Europeo de Referencia para las Lenguas (MCER, 2002: 110): «un conjunto de principios que rigen el ensamblaje de elementos en compendios (oraciones) con significado, clasificados y relacionados entre sí».

A partir de esta concepción, la competencia lingüística o gramatical puede ser definida como «el conocimiento de los recursos gramaticales de una lengua y la capacidad de utilizarlos» (MCER, 2002: 110).

Aun así, el propio documento del MCER advierte que «la gramática de cualquier lengua es enormemente compleja, y hasta ahora se resiste a un tratamiento concluyente o exhaustivo. Hay varias teorías y modelos en conflicto sobre la organización de palabras en oraciones» (MCER, 2002: 110). En ese sentido, no es objetivo nuestro valorar el uso de una u otra forma, sino más bien observar las interferencias que la lengua portuguesa (lengua materna) ejerce sobre el empleo de la lengua española por aprendices brasileños de español. Nos limitamos, por ende, a analizar los errores que dicha interferencia causa y, así, buscar los posibles orígenes de estos errores.

Quisiéramos aclarar también en este apartado que la competencia lingüística a que nos referimos se trata de una subcompetencia lingüística o gramatical del alumno, en tanto ésta está subyacente a la competencia comunicativa o competencia en la lengua.

El modelo de Celce-Murcia, Dörnyei y Thurrell (1995) permite aclarar mejor esa subdivisión: 


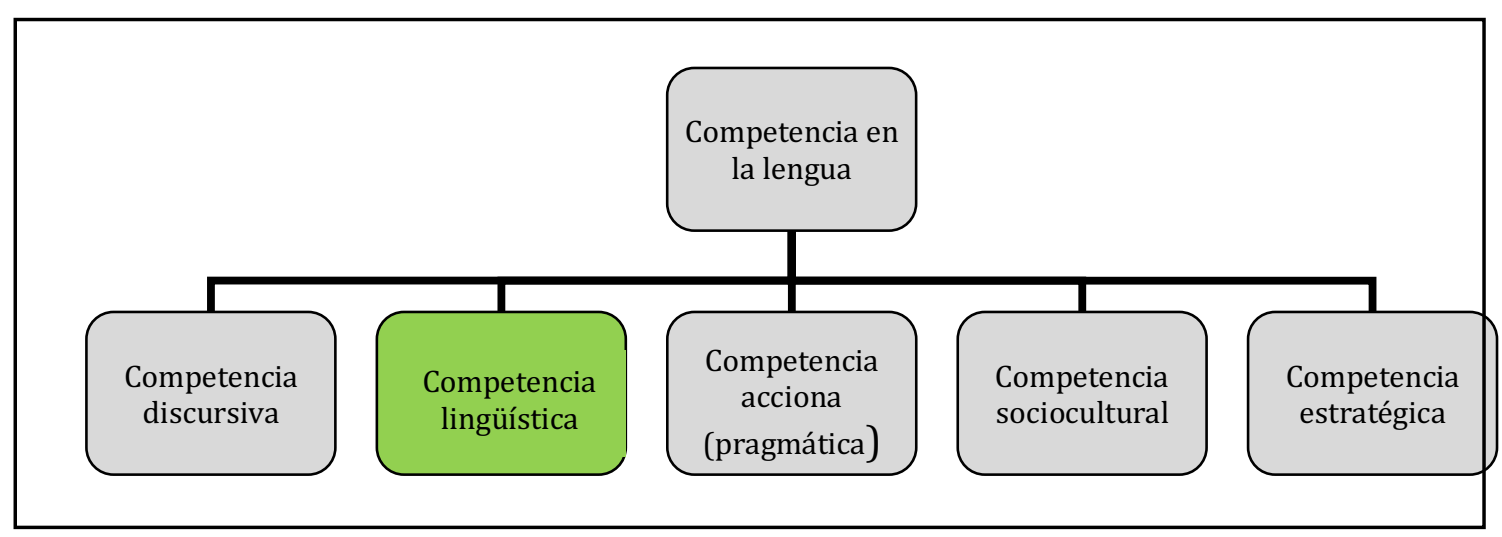

Diagrama: Competencia en la lengua - Modelo deCelce-Murcia, Dörnyei y

Thurrell (1995) (Fuente: Lobato y Gargallo, 2004: 457)

Se hace relevante destacar que en la competencia lingüística están subyacentes las cuatro habilidades: expresión oral, expresión escrita, comprensión auditiva y comprensión lectora.

El concepto de competencia lingüística denominado también como gramatical se debe al hecho de que:

La gramática ha constituido uno de los niveles de descripción y explicación del sistema de las lenguas, responsable de sus componentes morfológicos y sintácticos; junto a ella existen otros dos niveles en la descripción del sistema: la semántica, que se ocupa del léxico y del significado, y la fonética, que se ocupa de los sonidos. Más recientemente ha venido a añadirse a estos niveles un nuevo campo de descripción y explicación, más allá del sistema: el uso de la lengua, del que es responsable la pragmática. (Martín Peris, 2004: 468)

En ese sentido se ve que el concepto de competencia gramatical se ha ampliado, lo que justifica la denominación «competencia lingüística».

Como nuestro interés de estudio se enmarca en el análisis de errores interlinguales, se sitúa dentro del campo de las habilidades lingüísticas. Así, hemos elegido la subcompetencia lingüística, la cual comprende las cuatro habilidades, y nos detenemos en una de ellas - la expresión escrita - con la intención de delimitar aún más nuestra investigación. 


\subsection{La expresión escrita en LE}

Hemos elegido la expresión escrita como objeto de investigación. Además, hemos tenido en cuenta la importancia de este recurso en los ámbitos académico y profesional. De igual modo, dicha importancia también se destaca en el entorno de aprendizaje de una lengua extranjera.

Según Cassany (2004: 917-920):

[...] escribir constituye una potente herramienta de mediación en la apropiación de cualquier contenido y habilidad (...) el aprendiz que aspira a producir escritos con eficacia en la comunidad hispana debe aprender a utilizar el lenguaje de modo diferente a como lo utiliza en el habla, en su lengua materna o en la L2 que está aprendiendo.

Saíz (2010) también expone los beneficios de la práctica de la escritura: «la expresión escrita es una destreza que permite al aprendiz desarrollar tanto las competencias comunicativas (lingüística, pragmática y sociolingüística) como algunas de las competencias generales (saber hacer, saber aprender y saber ser)» (Saíz, 2010: 2). Además, la escritura es también un puente de acceso al conocimiento. En ese sentido, Sánchez (2009: 21) agrega: «la escritura es una herramienta imprescindible en el aprendizaje de una lengua extranjera para la adquisición de nuevos datos y destrezas, pues se convierte en un medio para adquirir otros conocimientos».

\subsection{La destreza escrita en los exámenes del CELU}

En las producciones escritas en el examen del CELU, los candidatos deben atender a los criterios de adecuación discursiva, gramatical y léxica de contenido, en el domino de la lengua en su uso académico, laboral o informativo.

El candidato que alcance el certificado del CELU en el nivel intermedio puede redactar, con poca complejidad y poco detalle, distintos tipos de textos: cartas informales y formales, textos instructivos, relatos, ensayos, artículos de opinión, informes en general. Por su parte, en el nivel avanzado, ya será capaz de redactar una amplia variedad de textos claros, precisos y adecuados: cartas informales y formales, textos instructivos, relatos, ensayos, resúmenes, artículos de opinión, informes laborales o académicos. 


\subsection{La categoría «verbo» en la gramática}

Según Torrego (2005: 14), «en el estudio de las clases de palabras intervienen tanto la Sintaxis (combinación de palabras, funciones) como la Morfología (la estructura interna de la palabra)». Es decir, los estudios morfológicos no se refieren sólo a clases de palabras, ni tampoco los sintácticos se refieren sólo a oraciones.

La Morfosintaxis, por tanto, es el estudio en el cual intervienen tanto la Morfología como la Sintaxis y el que trata no sólo del análisis del orden de los signos lingüísticos dentro de la oración, sino también, nos permite simultáneamente el estudio de la construcción de palabras.

En esa línea, el presente estudio pone foco al análisis de la categoría «verbos». Torrego (2005: 134) presenta el verbo como una clase de palabras o categoría léxica que tiene algunas características específicas: a) forma (compuesta de raíz (o lexema) y desinencias (morfemas) que se adhieren a la raíz y expresan significados: tiempo, modo, aspecto, persona, número); b) conjugación (unión de las desinencias a la raíz del verbo, y cada una representa un significado); c. función (siempre presenta el núcleo sintáctico del predicado de la oración).

De ahí, nos centraremos al análisis de los errores de aprendices brasileños de español, en el empleo de los verbos en lengua española, teniendo en cuenta sus producciones de textos escritos y lo que quisieron expresar en la escritura (con base a las consignas de las actividades) para, partiendo de dicho contexto, identificar los errores y sus posibles causas.

\section{Criterios utilizados en nuestro estudio para el análisis de las interferencias}

La utilización de criterios para la clasificación de los tipos de interferencias en un proceso de investigación es un instrumento necesario para facilitar dicha clasificación y depende, como es lógico, del objetivo del estudio. Es posible, aun, mezclar taxonomías si el objetivo así lo requiere.

Para atender a nuestro objetivo de estudio, utilizamos los siguientes criterios: el criterio lingüístico/gramatical, el criterio descriptivo y el criterio etiológico. Para la definición de estos criterios, tuvimos en cuenta los estudios de Corder (1973/1992: 
273-274), Vázquez (1986, 1991, 1999, citado en Gargallo, 2004: 404-405) y Fernández (1997: 29-30).

Criterio lingüístico/gramatical: tiene como base los diferentes niveles del sistema lingüístico (fonético-fonológico-ortográfico, léxico-semántico, morfosintaxis, discurso) y las categorías que son afectadas por los errores. Basándonos en este criterio, nuestro estudio se centra en los errores de naturaleza morfosintáctica que ocurren en las construcciones con verbos.

Criterio descriptivo: implica explicar los errores, las estrategias del aprendiz o las reglas lingüísticas seguidas por los hablantes. En nuestro estudio, el criterio descriptivo expresa las siguientes estrategias del aprendiz: omisión; elección falsa; colocación innecesaria (adición); forma errónea; y colocación falsa.

Alexopoulou (2006: 21-22) describe sucintamente qué comprende cada una de estas estrategias:

1. Omisión: ausencia de un morfema o de una palabra que debería aparecer. Ej.: *espero verte _ próxima semana

2. Elección falsa: elección de un morfema o de una palabra incorrecta en un determinado contexto. En gran parte de los casos se trata de la sustitución de una unidad gramatical por otra. Ej.: *Vivo a Atenas

3. Colocación innecesaria: adición o presencia injustificada de un morfema o de una palabra que no debería aparecer. Ej.: *un otro día

4. Forma errónea: uso de una forma errónea de un morfema o de una estructura en lugar de otra que sería la correcta. Este tipo de error es típicamente formal y refleja el desconocimiento o inobservancia de las reglas gramaticales. Ej.: *penso

5. Colocación falsa: se trata del empleo incorrecto de un morfema o conjunto de morfemas que alternan la estructura sintagmática del enunciado. Por ejemplo, orden 'adjetivo/sustantivo' en lugar de 'sustantivo/adjetivo': *la civil guerra

Criterio etiológico: considera el origen de las interferencias lingüísticas en el proceso de aprendizaje-adquisición de una LE. Los errores producidos por interferencia de la lengua materna, o de otra LE de dominio del aprendiz, se conocen como 'interlinguales' o 'interlingüísticos'. Los errores que pueden ser causados por conflicto interno de las reglas de la LE se dominan 'intralinguales' o 'intralingüísticos'. Según Vázquez (1999: 34), la similitud de la lengua meta con la lengua materna y la correspondencia casi automática entre esas dos lenguas favorecen la interferencia. 
A continuación se ve una muestra de cómo estos criterios se distribuyen y se emplean en nuestro estudio. En la transcripción del error, lo destacamos en fuente negrita y color rojo, de modo a favorecer la visualización del fallo en el análisis.
1. Verbos
1.1 Flexión verbal
Criterio lingüístico
- Errores interlingüísticos

\section{Criterio etiológico}

- Omisión, por interferencia de la lengua materna, de la ' $r$ ' en el infinitivo añadido de pronombre átono Criterio Descriptivo

\begin{tabular}{|c|c|c|}
\hline \multicolumn{2}{|c|}{ Producción de un aprendiz } & \multicolumn{2}{c|}{ Formas correctas } \\
\hline $\begin{array}{c}\text { "estaba muy cansado de } \\
\text { transportala" }\end{array}$ & $\begin{array}{c}\text { En } \\
\text { portugués }\end{array}$ & En español \\
\cline { 2 - 4 } & la) & (transportá- \\
\hline
\end{tabular}

- Errores intralingüísticos $\longrightarrow$ Criterio etiológico

- Elección falsa al emplear la primera persona del singular en un contexto que requiere la tercera persona del singular en el Pretérito Indefinido.

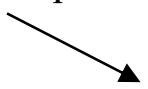

Criterio Descriptivo

\begin{tabular}{|c|l|}
\hline Producción de un aprendiz & Forma correcta en español \\
\hline $\begin{array}{c}\text { "...estoy en Itaguí, donde vino a } \\
\text { trabajar..." }\end{array}$ & (vine) \\
\hline
\end{tabular}

Cuadro 1: Muestra del empleo de criterios en la clasificación de errores

\section{Errores en la categoría «verbos»}

Para el análisis de la escritura de los informantes, se puso foco en dos géneros diferentes de textos: carta familiar y artículo de opinión, contemplados en los exámenes del CELU. Los niveles de dominio en la lengua considerados fueron el intermedio y el avanzado. Ambos niveles produjeron los dos géneros. 
La elección del análisis de estos géneros se debe a la oportunidad de realizar el análisis de errores en un contexto que permitiera un lenguaje más sencillo (informal) y en otro que exigiera un lenguaje más bien elaborado (formal).

Tras una exhaustiva tarea de análisis e identificación de errores, se verificó que, dentro de todas las categorías de errores identificadas, la dificultad mayor de los brasileños está en el uso correcto de los verbos en español. O sea, la categoría «verbos» es la que presenta un número más expresivo de errores, sobre todo a lo que se refiere a flexión verbal y empleo de los tiempos verbales. El gráfico 1 proporciona una visión clara de esto.

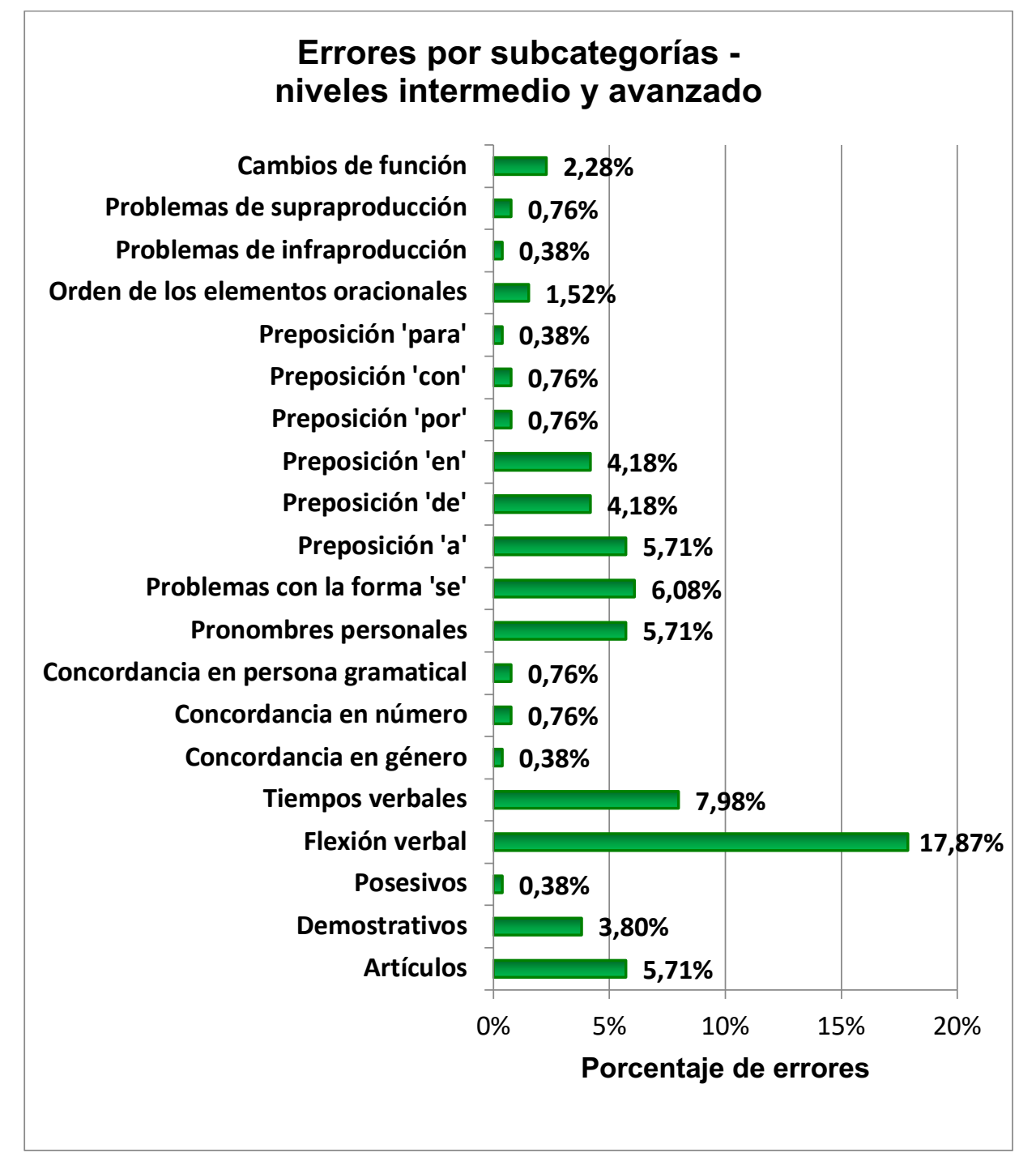

Gráfico 1: Distribución por subcategorías de errores con base en los errores totales 
Los errores en los verbos son los más numerosos, corresponden a un 25,85\% de los errores totales. Aquí se registran los errores de flexión verbal (un 17,87\%) y de tiempos verbales (un 7,98\%).

En cuanto a la procedencia etiológica de los fallos, observamos que, del total de los errores con verbos, un 83,82\% son interlingüísticos y un 16,18\% son intralingüísticos, como se aprecia en el gráfico 2.

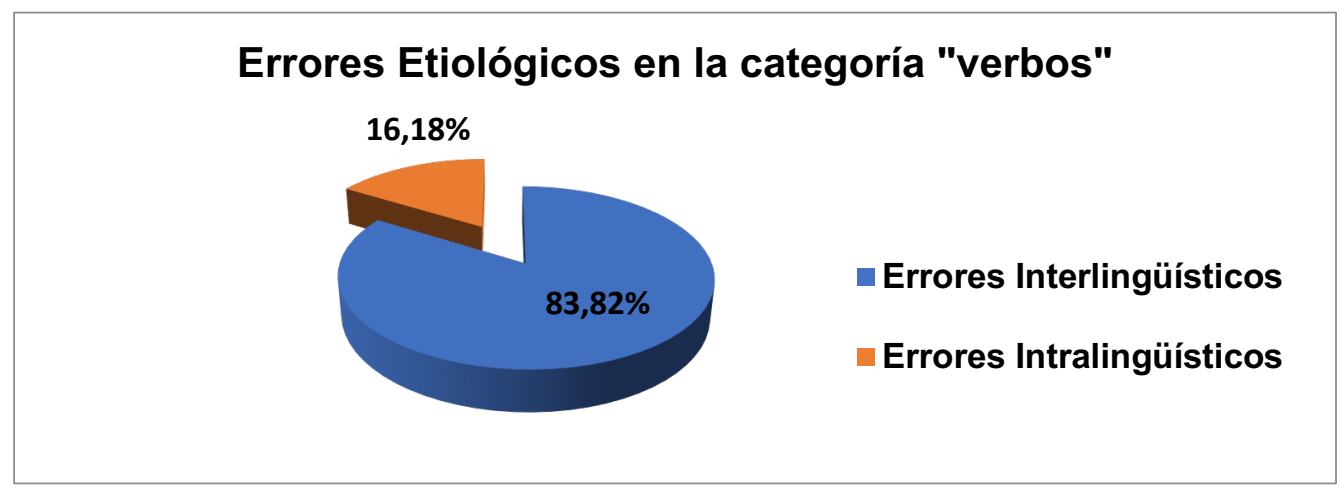

Gráfico 2: Distribución y frecuencia de errores con base en los errores totales con verbos

También, el cuadro 2 permite conocer la frecuencia (porcentual) del origen de los errores (interlingüísticos o intralingüísticos) en las subcategorías «flexión verbal»y «tiempos verbales».

\begin{tabular}{|l|c|c|}
\hline \multirow{2}{*}{$\begin{array}{l}\text { Categoría de los } \\
\text { errores }\end{array}$} & $\begin{array}{c}\text { Interlingüíst } \\
\text { icos }\end{array}$ & $\begin{array}{c}\text { Intralingüíst } \\
\text { icos }\end{array}$ \\
\cline { 2 - 3 } & $\mathbf{( \% )}$ & $\mathbf{( \% )}$ \\
\hline Verbos & $\mathbf{8 3 , 8 2}$ & $\mathbf{1 6 , 1 8}$ \\
\hline Flexión verbal & 85,10 & 14,90 \\
\hline Tiempos verbales & 80,95 & 19,05 \\
\hline
\end{tabular}

Cuadro 2: Distribución y frecuencia de errores por categorías 


\subsection{Descripción y clasificación de los errores y origen de los fallos}

En esta sección presentamos y describimos los errores identificados en la interlengua escrita de brasileños hablantes de español, de nivel intermedio y avanzado.

\subsubsection{Errores de flexión verbal}

\section{- Errores interlingüísticos}

Forma errónea al emplear el infinitivo conjugado por interferencia de la lengua materna y analogía con esta.

\begin{tabular}{|l|l|l|}
\hline Producción de un aprendiz & \multicolumn{2}{|c|}{ Formas correctas } \\
\hline \multirow{2}{*}{ "protegermos" } & En portugués & En español \\
\cline { 2 - 3 } & (protegermos) & (protegernos) \\
\hline
\end{tabular}

Omisión, por interferencia de la lengua materna, de la ' $r$ ' en el infinitivo añadido de pronombre átono.

\begin{tabular}{|c|l|l|}
\hline \multicolumn{2}{|c|}{ Producciones de los aprendices } & \multicolumn{2}{|c|}{ Formas correctas } \\
\hline \multirow{2}{*}{$\begin{array}{c}\text { "estaba muy cansado de } \\
\text { transportala" }\end{array}$} & En portugués & En español \\
\cline { 2 - 3 } "te invito a disfrutalo" & (transportá-la) & (transportarla) \\
\hline
\end{tabular}

Empleo de forma errónea por interferencia de la lengua materna o analogía a esta y al verbo 'ser' bien en español, bien en portugués.

\begin{tabular}{|l|l|l|}
\hline Producciones de los aprendices & \multicolumn{2}{|c|}{ Formas correctas } \\
\hline \multirow{2}{*}{ "estea" } & En portugués & En español \\
\cline { 2 - 3 } & (esteja) & (esté) \\
\hline "estean" & (estejam) & (estén) \\
\hline
\end{tabular}

Forma errónea al flexionar la terminación del verbo en Futuro Simple cuando, en verdad, se pretende expresar el Pretérito Indefinido. 


\begin{tabular}{|l|l|l|}
\hline Producción de un aprendiz & \multicolumn{2}{|c|}{ Formas correctas } \\
\hline \multirow{2}{*}{ "votarán" } & En portugués & En español \\
\cline { 2 - 3 } & (votaram) & (votaron) \\
\hline
\end{tabular}

Forma errónea al flexionar la terminación del verbo en Pretérito Imperfecto de Subjuntivo cuando, en verdad, se pretende expresar el Pretérito Indefinido.

\begin{tabular}{|l|l|l|}
\hline Producción de un aprendiz & \multicolumn{2}{|c|}{ Formas correctas } \\
\hline \multirow{2}{*}{ "Esas iniciativas me encantaran" } & En portugués & En español \\
\cline { 2 - 3 } & (encantaram) & (encantaron) \\
\hline
\end{tabular}

Forma errónea al flexionar el verbo 'venir' en segunda persona del singular del Imperativo Afirmativo cuando, en verdad, se pretende expresarlo en tercera persona del singular del Presente de Indicativo, por interferencia de la forma como es conjugado, en Presente, en la lengua materna.

\begin{tabular}{|c|l|l|}
\hline Producción de un aprendiz & \multicolumn{2}{|c|}{ Formas correctas } \\
\hline \multirow{3}{*}{$\begin{array}{c}\text { "La Organización Internacional del } \\
\text { Trabajo ven" }\end{array}$} & En portugués & En español \\
\cline { 2 - 3 } & & (vem) \\
\hline
\end{tabular}

Empleo de formas erróneas en algunas conjugaciones, por interferencia de la lengua materna.

\begin{tabular}{|l|l|l|}
\hline Producciones de los aprendices & \multicolumn{2}{|c|}{ Formas correctas } \\
\hline \multirow{2}{*}{ "expono" } & En portugués & En español \\
\cline { 2 - 3 } & $($ exponho) & (expongo) \\
\hline "trace muchos daños" & $($ traz $)$ & $($ trae $)$ \\
\hline "trajendo" & & $($ trayendo) \\
\hline
\end{tabular}


Forma errónea en el empleo del verbo conjugado en tercera persona del singular (formal) en un contexto que requiere la conjugación en segunda persona del singular (informal) en el Presente de Indicativo. ${ }^{1}$

\begin{tabular}{|l|c|c|}
\hline Producciones de los aprendices & \multicolumn{2}{|c|}{ Formas correctas } \\
\hline \multirow{2}{*}{ "tú que no tieneproblemas" } & En portugués & En español \\
\cline { 2 - 3 } & $\begin{array}{c}\text { (você que não } \\
\text { tem problemas) }\end{array}$ & (tienes) \\
\hline "tú sabe" & (você sabe) & (sabes) \\
\hline
\end{tabular}

Forma errónea al realizar la transitivización del verbo 'gustar' por interferencia de la lengua materna en analogía a la conjugación del verbo «gostar de» en portugués (eu gosto de, tu gostas de, ele(a)/você gosta de...).

\begin{tabular}{|l|c|c|}
\hline Producción de un aprendiz & \multicolumn{2}{|c|}{ Formas correctas } \\
\hline \multirow{2}{*}{ "a ti te gustas trabajar" } & En portugués & En español \\
\cline { 2 - 3 } & $\begin{array}{c}\text { (tu gostas de } \\
\text { trabalhar })\end{array}$ & $(\ldots$ te gusta...) \\
\hline
\end{tabular}

Forma errónea en el empleo de algunas letras por interferencia de la lengua materna o analogía a esta, bien sea por su inclusión modificativa en la raíz del verbo o como alteración de su conjugación por transposición del modelo portugués.

\begin{tabular}{|l|l|l|}
\hline Producciones de los aprendices & \multicolumn{2}{|c|}{ Formas correctas } \\
\hline \multirow{2}{*}{ "sustenerse" } & En portugués & En español \\
\cline { 2 - 3 } & (sustentar-se) & (sostenerse) \\
\hline "somado" & (somado) & (sumado) \\
\hline "viver" & (viver) & (vivir) \\
\hline "percebí" & (percebi) & (percibí) \\
\hline
\end{tabular}

1 Esta confusión se da debido al hecho de que en el portugués de Brasil el pronombre de tratamiento 'você' es utilizado en situación informal y es conjugado en tercera persona. Sin embargo, no hay distinción en la conjugación del verbo para contextos formales o informales, dado que el pronombre de tratamiento formal generalmente utilizado 'senhor' /'senhora' también requiere la conjugación verbal en tercera persona. Así que lo usual es la conjugación de tercera persona, sea en singular, sea en plural, en ambos contextos. 
Empleo de formas erróneas provocadas por el cambio en el orden de las letras o colocación innecesaria de letras, debido a la interferencia de la lengua materna.

\begin{tabular}{|l|l|l|}
\hline Producciones de los aprendices & \multicolumn{2}{|c|}{ Formas correctas } \\
\hline \multirow{2}{*}{ "prejudiquen" } & En portugués & En español \\
\cline { 2 - 3 } & (prejudiquem) & (perjudiquen) \\
\hline "oferecidos" & (oferecidos) & (ofrecidos) \\
\hline "estabelecidos" & (estabelecidos) & (establecidos) \\
\hline
\end{tabular}

Forma errónea provocada por el cambio de la 'n' por ' $m$ ', por interferencia de la lengua materna, en la marcación del plural en verbos de $3^{\underline{a}}$ persona en el Presente de Indicativo.

\begin{tabular}{|l|l|l|}
\hline Producciones de los aprendices & \multicolumn{2}{|c|}{ Formas correctas } \\
\hline \multirow{2}{*}{ "aspiram" } & En portugués & En español \\
\cline { 2 - 3 } & (aspiram) & (aspiran) \\
\hline "apuntam" & (apuntam) & (apuntan) \\
\hline "permitem" & (permitem) & (permiten) \\
\hline "reúnem" & (reúnem) & (reúnen) \\
\hline
\end{tabular}

Forma errónea al emplear diptongación por analogía a la lengua materna.

\begin{tabular}{|l|l|l|}
\hline Producción de un aprendiz & \multicolumn{2}{|c|}{ Formas correctas } \\
\hline \multirow{2}{*}{ "aproveichar" } & En portugués & En español \\
\cline { 2 - 3 } & (aproveitar) & (aprovechar) \\
\hline
\end{tabular}

Forma errónea en la diptongación de la vocal tónica (-ie / -ue) que en unos casos no es aplicada por analogía a la lengua materna o interferencia de ella.

\begin{tabular}{|l|l|l|}
\hline Producciones de los aprendices & \multicolumn{2}{|c|}{ Formas correctas } \\
\hline \multirow{2}{*}{ “pensas" } & En portugués & En español \\
\cline { 2 - 3 } & (pensas) & (piensas) \\
\hline "queren" & (querem) & (quieren) \\
\hline
\end{tabular}




\begin{tabular}{|l|l|l|}
\hline "un chico empeza" & (começa) & (empieza) \\
\hline "comendo" & (comendo) & (comiendo) \\
\hline "sabendo" & (sabendo) & (sabiendo) \\
\hline "ponendolos" & (pondo-os)* & (poniéndolos) \\
\hline "vivindo" & (vivendo) & (viviendo) \\
\hline "esforzo" & (esforço) & (esfuerzo) \\
\hline "uno simplemente la colga" & (colga) & (cuelga) \\
\hline "podes imaginar" & (podes) & (puedes) \\
\hline
\end{tabular}

* Verbo irregular también en portugués.

Forma errónea en la diptongación de la vocal tónica que es suprimida y, junto a ello, permanecen rasgos de la lengua materna en la conjugación.

\begin{tabular}{|l|l|l|}
\hline Producción de un aprendiz & \multicolumn{2}{|c|}{ Formas correctas } \\
\hline \multirow{2}{*}{ "conseguiron" } & En portugués & En español \\
\cline { 2 - 3 } & (conseguiram) & (consiguieron) \\
\hline
\end{tabular}

Forma errónea, por interferencia de la regla de la lengua materna, en la formación del gerundio irregular de algunos verbos.

\begin{tabular}{|l|l|l|}
\hline Producciones de los aprendices & \multicolumn{2}{|c|}{ Formas correctas } \\
\hline \multirow{2}{*}{ "dormindo" } & En portugués & En español \\
\cline { 2 - 3 } & (dormindo) & (durmiendo) \\
\hline "dormiendo" & (dormindo) & (durmiendo) \\
\hline "disminuindo" & (diminuindo) & (disminuyendo) \\
\hline
\end{tabular}

\section{- Errores intralingüísticos}

Elección falsa al emplear la primera persona del singular en un contexto que requiere la tercera persona del singular en el Pretérito Perfecto Compuesto.

\begin{tabular}{|l|l|}
\hline Producción de un aprendiz & Forma correcta en español \\
\hline "he causado" & (ha causado) \\
\hline
\end{tabular}


Elección falsa al emplear la primera persona del singular en un contexto que requiere la tercera persona del singular en el Pretérito Indefinido.

\begin{tabular}{|c|l|}
\hline Producción de un aprendiz & Forma correcta en español \\
\hline $\begin{array}{c}\text { “...estoy en Itagüí, donde vino a } \\
\text { trabajar..." }\end{array}$ & (vine) \\
\hline
\end{tabular}

Colocación innecesaria de diptongación por sobregeneralización de esta regla en la lengua objeto.

\begin{tabular}{|l|l|}
\hline Producciones de los aprendices & Formas correctas en español \\
\hline "compruebado" & (comprobado) \\
\hline "espiero" & (espero) \\
\hline
\end{tabular}

Empleo de forma errónea al sobregeneralizar la irregularidad de verbos que sufren cambios en la raíz de la -e por -i en algunos tiempos verbales, pero no en otros.

\begin{tabular}{|l|l|}
\hline Producción de un aprendiz & Forma correcta en español \\
\hline "consiguirán" & (conseguirán) \\
\hline
\end{tabular}

Forma errónea al sobregeneralizar la regla aplicada a verbos irregulares que en la conjugación tienen añadida a su raíz la 'y'.

\begin{tabular}{|l|l|}
\hline Producción de un aprendiz & Forma correcta en español \\
\hline "creyemos" & (creemos) \\
\hline
\end{tabular}

\subsubsection{Errores en el empleo de los tiempos verbales}

\section{- Errores interlingüísticos}

Forma errónea en el empleo del Futuro del Subjuntivo (en desuso en la lengua española), en el cual se flexiona el infinitivo, por analogía a la lengua materna, en lugar del Presente del Subjuntivo. 


\begin{tabular}{|c|c|c|}
\hline Producciones de los aprendices & \multicolumn{2}{|c|}{ Formas correctas } \\
\hline \multirow[b]{2}{*}{ "cuando volveren" } & En portugués & En español \\
\hline & $\begin{array}{l}\text { (quando } \\
\text { voltarem) }\end{array}$ & $\begin{array}{l}\text { (cuando } \\
\text { vuelvan) }\end{array}$ \\
\hline "para descansaren y trataren" & $\begin{array}{l}\quad \text { (para } \\
\text { descansarem } \\
\text { tratarem) }\end{array}$ & $\begin{array}{l}\quad \text { (para } \\
\text { descansen } \\
\text { traten) }\end{array}$ \\
\hline "además de no opinaren" & $\begin{array}{l}\text { (além de não } \\
\text { opinarem) }\end{array}$ & $\begin{array}{c}\text { (además de } \\
\text { que no opinen) }\end{array}$ \\
\hline "el hecho de trabajaren" & $\begin{array}{rr}(0 \quad \text { fato } & \text { de } \\
\text { trabalharem })\end{array}$ & $\begin{array}{l}\text { (el hecho de } \\
\text { que trabajen) }\end{array}$ \\
\hline "sin teneren que trabajar" & $\begin{array}{l}\text { (sem terem } \\
\text { que trabalhar) }\end{array}$ & $\begin{array}{l}\text { ( } \sin \\
\text { tengan } \\
\text { trabajar })\end{array}$ \\
\hline "para disfrutaren" & $\begin{array}{c}\text { (para } \\
\text { desfrutarem) }\end{array}$ & $\begin{array}{c}\text { (para } \\
\text { disfruten) }\end{array}$ \\
\hline
\end{tabular}

Forma errónea en el empleo del Futuro del Subjuntivo (en desuso en la lengua española), por analogía a la lengua materna, en lugar del Presente de Indicativo.

\begin{tabular}{|c|c|c|}
\hline Producciones de los aprendices & \multicolumn{2}{|c|}{ Formas correctas } \\
\hline \multirow{2}{*}{ "además de representaren" } & En portugués & En español \\
\cline { 2 - 3 } & $\begin{array}{c}\text { (além de } \\
\text { representarem) }\end{array}$ & $\begin{array}{c}\text { (además de } \\
\text { que representan) }\end{array}$ \\
\hline \multirow{2}{*}{ "por no seren trabajadores dentro de } & $\begin{array}{c}\text { (por não serem } \\
\text { trabalhadores } \\
\text { lentro da lei) }\end{array}$ & $\begin{array}{c}\text { (debido a que } \\
\text { no son trabajadores } \\
\text { dentro de la ley) }\end{array}$ \\
\hline
\end{tabular}

Forma errónea en el empleo de perífrasis distintas (que no se utilizan en español) para expresar un hecho pasado aún en ocurrencia, en lugar de emplear el Pretérito Perfecto Compuesto, por interferencia y transferencia errónea de la lengua materna.

\begin{tabular}{|c|c|c|c|}
\hline Producción de un aprendiz & \multicolumn{3}{|l|}{ Formas correctas } \\
\hline \multirow{2}{*}{$\begin{array}{l}\text { "tengo conocido y aprendido mucho } \\
\text { de la cultura" }\end{array}$} & En portugués & $\begin{array}{r}\text { En } \\
\text { español }\end{array}$ & \\
\hline & $\begin{array}{l}\text { (tenho } \\
\text { visto/conhecido } \\
\text { aprendido muito...) }\end{array}$ & $\begin{array}{c}\text { (he } \\
\text { conocido } \\
\text { aprendido } \\
\text { mucho...) }\end{array}$ & $\mathrm{y}$ \\
\hline
\end{tabular}


Forma errónea en la formación del infinitivo de verbos, por interferencia de la lengua materna.

\begin{tabular}{|l|l|l|}
\hline Producción de un aprendiz & \multicolumn{2}{|c|}{ Formas correctas } \\
\hline \multirow{2}{*}{ "garantir" } & En portugués & En español \\
\cline { 2 - 3 } & (garantir) & (garantizar) \\
\hline
\end{tabular}

Elección falsa en la utilización del gerundio de posterioridad por interferencia de la lengua materna y analogía a esta.

\begin{tabular}{|c|c|c|}
\hline Producción de un aprendiz & \multicolumn{2}{|c|}{ Formas correctas } \\
\hline \multirow[b]{2}{*}{$\begin{array}{l}\text { “...y allí se quedaron todo el día, } \\
\text { dormitando, comendo, jugando cartas, } \\
\text { pintando..." }\end{array}$} & Em portugués & Em español \\
\hline & $\begin{array}{l}\text { (...e ali ficaram } \\
\text { todo o dia, } \\
\text { cochilando, } \\
\text { comendo, jogando } \\
\text { cartas, pintando ou } \\
\text { fazendo qualquer } \\
\text { coisa...) }\end{array}$ & $\begin{array}{l}\qquad(\ldots y \text { allí se } \\
\text { quedaron todo el } \\
\text { día, dormitaron, } \\
\text { comieron, jugaron } \\
\text { a las cartas, } \\
\text { pintaron...) }\end{array}$ \\
\hline
\end{tabular}

Elección falsa en el empleo del Gerundio donde se requiere el Infinitivo por interferencia de la lengua materna y analogía a esta.

\begin{tabular}{|c|l|l|}
\hline Producciones de los aprendices & \multicolumn{2}{|c|}{ Formas correctas } \\
\hline \multirow{2}{*}{$\begin{array}{c}\text { "Muy grande fue mi sorpresa cuando, } \\
\text { llegando allá,..." }\end{array}$} & $\begin{array}{c}\text { En portugués } \\
\text { (...quando, } \\
\text { chegandolá,...) }\end{array}$ & $\begin{array}{c}\text { En español } \\
\text { allá,...) }\end{array}$ \\
\hline "come te sienta' sabendo que..." & $\begin{array}{l}(\text { como você se } \\
\text { sente sabendo } \\
\text { que...) }\end{array}$ & $\begin{array}{l}(\text { cómo te te } \\
\text { sientes al saber } \\
\text { que...) }\end{array}$ \\
\hline
\end{tabular}

Forma errónea que resulta problemas aspectuales al emplear construcciones menos precisas y pobres, 'estar + gerundio', debido a un vicio ${ }^{2}$ de lenguaje que el 
aprendiz presenta en el uso excesivo del gerundio en la lengua materna y lo transfiere a la lengua meta.

\begin{tabular}{|c|c|c|}
\hline Producciones de los aprendices & \multicolumn{2}{|c|}{ Formas correctas } \\
\hline & En portugués & En español \\
\hline $\begin{array}{l}\text { "Van a estar siempre logrando } \\
\text { subempleos" }\end{array}$ & $\begin{array}{r}\text { (Sempre } \\
\text { conseguirão) }\end{array}$ & $\begin{array}{l}\text { (Siempre } \\
\text { lograrán) }\end{array}$ \\
\hline $\begin{array}{l}\text { "En el mundo } 120 \text { millones de niños } \\
\text { están trabajando" }\end{array}$ & $\begin{array}{l}\quad \text { (milhões de } \\
\text { meninos } \\
\text { trabalham) }\end{array}$ & $\begin{array}{l}\text { (millones de } \\
\text { niños trabajan) }\end{array}$ \\
\hline $\begin{array}{l}\text { "nosotros como sociedad estaremos } \\
\text { haciendo inconscientemente" }\end{array}$ & $\begin{array}{c}\text { (fazemos } \\
\text { inconscientemente) }\end{array}$ & $\begin{array}{c}\text { (hacemos } \\
\text { inconscientemente) }\end{array}$ \\
\hline "Niños y niñas... están recibiendo" & $\begin{array}{l}\text { (Meninos } \mathrm{e} \\
\text { meninas recebem) }\end{array}$ & $\begin{array}{l}\text { (Niños y niñas } \\
\text { reciben) }\end{array}$ \\
\hline
\end{tabular}

\section{- Errores intralingüísticos}

Elección falsa del Pretérito Imperfecto del Subjuntivo en lugar del Condicional del Indicativo debido a confusión entre estos tiempos verbales en la lengua meta.

\begin{tabular}{|c|c|}
\hline Producción de un aprendiz & Forma correcta en español \\
\hline $\begin{array}{l}\text { "¿Por qué será que los suizos no } \\
\text { quisieron ampliar sus vacaciones de } \\
\text { cuatro a seis semanas anuales? ¿Qué tipo } \\
\text { de desventajas hubieran obtenido? } \\
\text { ¿Desempleo masivo? ¿Salarios más } \\
\text { bajos?..." }\end{array}$ & $\begin{array}{l}\text { (...¿Qué tipo de desventajas habrían } \\
\text { obtenido?...) }\end{array}$ \\
\hline
\end{tabular}

Forma errónea en el empleo del Presente de Indicativo donde se requiere el Presente del Subjuntivo, debido a confusión en la desinencia verbal del verbo 'poseer' que lleva doble 'e' en su construcción de infinitivo en la lengua objeto.

\begin{tabular}{|c|c|}
\hline Producción de un aprendiz & Forma correcta en español \\
\hline $\begin{array}{l}\text { "mandarlos a la escuela } y \text { ahí } \\
\text { mantenerlos hasta } \\
\text { condiciones" }\end{array}$ & (...hasta que posean) \\
\hline
\end{tabular}


Elección falsa por regularización y sobregeneralización del sistema lingüístico al añadir a la raíz de un sustantivo la desinencia -ar para tenerse un verbo (se crea una forma verbal nueva a partir del sustantivo).

\begin{tabular}{|l|l|}
\hline Producción de un aprendiz & Forma correcta en español \\
\hline [broma] "bromar" & (bromear) \\
\hline [semilla] "semillar" & (sembrar) \\
\hline
\end{tabular}

\section{Conclusiones}

Los paradigmas verbales presentan distintos problemas respecto a la flexión del verbo. En gran parte, estos problemas se deben a la interferencia de la lengua materna (errores interlingüísticos). Por otro lado, hay también errores, aunque con menor representatividad, ocasionados por la confusión en el uso de las reglas de la propia lengua objeto (errores intralingüísticos).

En cuanto al total de errores en la flexión verbal, observamos que un 85,10\% son de origen interlingüístico, mientras que un $14,90 \%$ son de causa intralingüística (datos disponibles en el Cuadro 2 de este artículo).

En el análisis de esta subcategoría, vemos que es la que presenta el número más elevado de equivocaciones. Observamos, además, que las cifras más elevadas de errores son de naturaleza interlingüística, debido a la semejanza entre el portugués y el español y, por ende, a la confusión, que hacen los aprendices, de las estructuras de esas dos lenguas. Eso viene a corroborar el hecho de que la similitud habida entre los dos idiomas no equivale a una facilidad. En ese sentido, vemos los verbos, y más específicamente la flexión verbal, como uno de los puntos de especial dificultad para los aprendices brasileños de español.

Los problemas con los tiempos verbales componen la segunda categoría con más errores (tras los problemas de flexión verbal). De los errores totales con los tiempos verbales, un $80,95 \%$ son interlingüísticos y, en cambio, un 19,05\% son intralingüísticos (datos disponibles en el Cuadro 2 de este artículo). También en la subcategoría de tiempos verbales los números nos muestran claramente que los errores más representativos son los interlingüísticos.

Hemos observado, respecto a los errores interlingüísticos, que algunos de estos son resultados de transferencias de carencias que el aprendiz tiene en su propia lengua 
materna. Dada la proximidad de las lenguas portuguesa y española, los aprendices brasileños, como hemos visto en los resultados también de este análisis, suelen muchas veces transferir estructuras de su propia lengua para la lengua española, sea por medio de analogías, transposiciones de estructuras o por sobregeneralización de reglas de su lengua materna al emplearlas también en la lengua meta. A partir de ahí, es posible, además, que el aprendiente brasileño de español que presente carencias acerca de determinadas reglas de la norma culta de su lengua materna, las transfiera también a la lengua española al aprenderla.

En este artículo hemos expuesto las dificultades que hablantes/aprendientes brasileños de español presentan en la lengua meta $\mathrm{y}$, tras análisis detallados, presentamos las dificultades de estos aprendices acerca del empleo de los verbos, y el origen de los fallos, considerando la lengua materna y la lengua objeto - el portugués y el español. No obstante, juzgamos relevante aclarar que «cometer errores es una parte inevitable y hasta necesaria del proceso de aprendizaje» y que «la corrección de los errores, precisamente, es la que nos proporciona el tipo de evidencia negativa necesaria para el descubrimiento de la regla o el concepto correctos» (Corder, 1971: 75).

Más allá de esta consideración, este estudio puede ser un auxilio para el profesor de ELE, quien puede utilizarlo para una reflexión acerca de la didáctica en el contexto de enseñanza-aprendizaje de ELE. Además, al conocer las causas del error, el profesor puede asumir el papel de mediador/orientador, por medio de una corrección evidenciadora, con foco en las dificultades del alumno, de modo de animarlo a asumir el papel de agente reflexivo en el proceso de enseñanza-aprendizaje, en el cual el alumno aprende con sus propios errores.

Finalmente, consideramos que el aprendiente, al reflexionar acerca de la causa etiológica de los errores, podrá más fácilmente analizar los factores específicos, de su propia lengua materna o de la lengua meta, que les llevan a cometer el error. Análisis este que servirá, por tanto, de facilitador acerca del aprendizaje de ELE.

\section{Referencias bibliográficas}

ALEXOPOULOU, A. (2006). «Los criterios descriptivo y etiológico en la clasificación de los errores del hablante no nativo: una nueva perspectiva». Porta Linguarum, (5): 17-35.

CASSANY I COMAS, D. (2004). «La expresión escrita». En: Lobato, J. S. y Gargallo, I. S., 2004. Vademécum para la formación de profesores. Madrid: SGEL: 917-942. 
CELU - Certificado de Español Lengua y Uso, [en línea]. Disponible en: http://www.celu.edu.ar/index.php?lang=es [Fecha de acceso: 20 de febrero de 2017].

CONSEJO DE EUROPA. (2001/2002). Marco común europeo de referencia para las lenguas: aprendizaje, enseñanza, evaluación. Madrid: Secretaría General Técnica del MEC, Anaya e Instituto Cervantes.

CORDER, S. P. (1971). «Idiosincratic dialects and error analysis». International Review of Aplied Linguistics, (9): 161-170. (Traducido al español: Dialectos idiosincrásicos y análisis de errores. En: Liceras, J. M., 1991. La adquisición de las lenguas extranjeras, p. 63-77. Madrid: Visor).

CORDER, S. P. (1973). Introducing Applied Linguistics. Harmondsworth: Penguin. (Traducción al español: 1992. Introducción a la lingüística aplicada. México: Limusa).

FERNÁNDEZ, S. (1997). Interlengua y análisis de errores en el aprendizaje de español como lengua extranjera. Madrid: Edelsa.

GÓMEZ SEIBANE, S. (2012). «Dificultades morfosintácticas de lusohablantes en el aprendizaje de español: explicaciones desde la historia de la lengua». Letra Viva, 10/1, 2012: 85-108.

Disponible en:

http://www.academia.edu/2162789/Dificultades_morfosint\%C3\%A1cticas_de_l usohablantes_en_el_aprendizaje_de_espa\%C3\%B1ol_explicaciones_desde_la_histo ria_de_la_lengua [Fecha de acceso: 07 de junio de 2018].

GÓMEZ TORREGO, L. (2005). Gramática didáctica del español. São Paulo: SM.

GÓMEZ TORREGO, L. (2007). Análisis sintáctico: teoría y práctica. Madrid: SM.

KRASHEN, S. (1977). «The monitor model for second language performance». En: Burt, Dulay y Finochiaro (eds.). Viewponts on english as a second language. Nueva York: Regentes. (Traducido en Liceras, J. M., 1992).

LOBATO, J. S.; GARGALLO, I S. (2004). Vademécum para la formación de profesores. Madrid: SGEL.

MERCOSUR, Secretaria del Mercosur. Quienes somos, [en línea]. Disponible en: http://www.mercosur.int/innovaportal/v/8436/2/innova.front/secretaria-delmercosur-_-sectores---areas---unidades[Fecha de acceso: 05 de agosto de 2018].

ORTIZ, C. (2011). "Análisis de interlengua en un corpus de portugués escrito de estudiantes castellano hablantes universitarios». Revista de Lingüística y Lenguas Aplicadas, (6): 71-82.

PASCHOALIN, M. A. y SPADOTO, N. T. (1996). Gramática teoria e exercícios. São Paulo: FTD.

PAVÓN, M. E. A. (2009). Análisis de Errores, contrastivo e interlengua, en estudiantes brasileños de español como segunda lengua: verbos que rigen preposición y/o ausencia de ella. Tesis doctoral. Universidad Complutense de Madrid.

PERIS, E. M. (2004). «La subcompetencia lingüística o gramatical». En: Lobato, J. S. y Gargallo, I. S., 2004. Vademécum para la formación de profesores. Madrid: SGEL: 467-489. 
POLAKOF, A. C. (2009). «Estudios de Lingüística Aplicada. Análisis de errores léxicosintáctico verbales en producciones escritas por aprendices brasileños de ELE». Estudios de Lingüística Aplicada, 27(49): 79-96.

ROCHA, C. B. (2013). Los errores léxicos en textos escritos en español por alumnos universitarios brasileños en formación como profesores de español lengua extranjera. Tesis Doctoral. Universitat de Barcelona. Disponible en: https://www.tdx.cat/bitstream/handle/10803/120580/CBR_TESIS.pdf?sequenc e=1\&isAllowed=y [Fecha de acceso: 07 junio de 2018].

SAÍZ, C. L. (2010). «Competencia discursiva escrita en los niveles Avanzado (B2) y Dominio (C1): la unidad textual en los manuales de ELE». MarcoELE, (11), pp. 1-25, [en línea]. Disponible en: http://marcoele.com/la-unidad-textual-en-losmanuales-de-ele/[Fecha de acceso: 20 de febrero de 2014].

SÁNCHEZ, D. (2009). «La expresión escrita en la clase de ELE». MarcoELE, (8), pp. 1-41 Universidad de Filipinas.

SILVA JÚNIOR, P. A. (2010). Análisis de Errores. Estudio de las estructuras verbales y discursivas en el aprendizaje del español - LE por parte de alumnos brasileños (producción escrita). Tesis doctoral. Universidad de Salamanca.

TARONE, E. (1983). «On the variability of interlanguage systems». En: Applied Linguistics, (4): 143-163. (Traducido en Liceras, J. M., 1992).

TORRIJOS, M. B. (2015). Errores del uso del español en estudiantes extranjeros: creación de una taxonomía y su etiquetado. Tesis Doctoral. Universitat Politècnica de València.

Disponible en:

https://www.researchgate.net/profile/Keith_Stuart2/publication/299210135_T hesis_supervised_3/links/56efbbea08aed17d09f884b9/Thesis-supervised-3.pdf [Fecha de acceso: 07 junio de 2018].

USP - Universidade de São Paulo. Centro Interdepartamental de Línguas. Certificado de Español Lengua y Uso: o que é?. [en línea]. Disponible en: http://clinguas.fflch.usp.br/content/certificado-de-espa\%C3\%B1ol-lengua-y-uso [Fecha de acceso: 05 de febrero de 2015].

VÁZQUEZ, G. (1999). ¿Errores? ¡Sin falta!. Madrid: Edelsa. 
